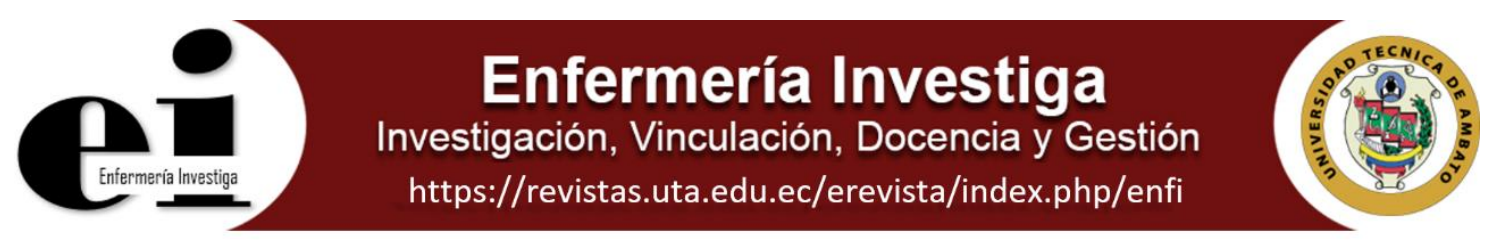

\title{
EL INCESTO EN ALGUNAS CORTES FARAÓNICAS Y SU REPERCUSIÓN SOBRE LA SALUD
}

\section{INCEST IN SOME PHARAONIC COURTS AND ITS IMPACT ON HEALTH}

Valdivia Herrero Lázaro Gerado1 http://orcid.org/0000-0001-7914-1516, García Orozco Lucas² http://orcid.org/0000-0002-9204-3416, Escalona Rabaza Milagros ${ }^{3}$ http://orcid.org/0000-0002-5782-8285, García Boyx Gabriela ${ }^{4}$ http://orcid.org/0000-0001-6759-8498, Arroyo Viera María José ${ }^{5}$ http://orcid.org/0000-0002-5748-2229, Bolaño Andrade Marco Andres 6 http://orcid.org/0000-0001-79477909, Guañuna Carpio Edwin Marcelo6 http://orcid.org/0000-0002-9839-0814.

1 Universidad de las Artes, Filial Santiago de Cuba, Cuba.

${ }^{2}$ Hospital Básico Asdrúbal de la Torre, Servicio de Cirugía General, Cotacachi, Ibarra, Ecuador.

${ }^{3}$ Hospital Básico Asdrúbal de la Torre, Servicio de Medicina General, Cotacachi, Ibarra - Ecuador.

${ }^{4}$ Universidad de Ciencias Médicas de Santiago de Cuba. Facultad de Medicina. Santiago de Cuba, Cuba.

${ }^{5}$ Hospital Básico Asdrúbal de la Torre-Servicio de Emergencias. Cotacachi, Ibarra, Ecuador.

${ }^{6}$ Hospital Básico Asdrúbal de la Torre- Servicio de Hospitalización. Cotacachi, Ibarra- Ecuador.

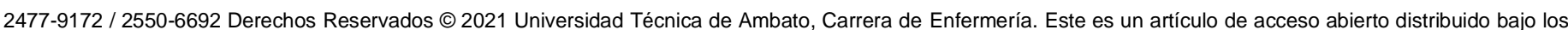

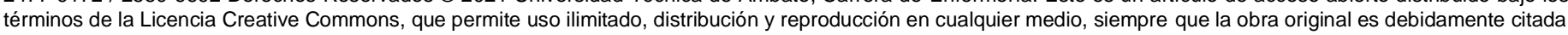

Recibido: 01 de octubre 2020

Aceptado: 26 de diciembre 2020

\section{RESUMEN}

Con la denominación de Antiguo Egipto se reconoce a una próspera y trascendental civilización de la Edad Antigua, cuna de todas las expresiones del intelecto humano, con una particular propensión por las manifestaciones artísticas, las ciencias, el comercio, la medicina y el culto religioso politeísta. Varios aspectos de índole histórica signaron la vida cotidiana en el Antiguo Egipto, entre los cuales llaman poderosamente la atención ciertos patrones conductuales en las dinámicas sexuales y reproductivas de los miembros de la corte faraónica, que no difieren de la percepción y el comportamiento que actualmente muchos individuos imitan, sobre todo en las sociedades occidentales. Fenómenos como el matrimonio a corta edad entre individuos emparentados consanguíneamente, manifiestan explícitamente que las uniones incestuosas era una costumbre ampliamente extendida en la familia real egipcia, con la intención expresa de mantener una descendencia pura, capaz de conservar el poder por mediación de la sucesión dinástica.

Palabras clave: Dinastía, faraón, incesto, reproducción, sexualidad.

\section{ABSTRACT}

The maintenance of postoperative fasting in patients undergoing major elective abdominal surgery is controversial, in the guild of clinical-surgical specialties. The divergences point to the resolution or aggravation of clinical factors such as paralytic ileus, expulsion of flatus, nausea, vomiting, diarrhea or dehiscence of intestinal sutures. The use of the diet, generally progressive, is not accepted by all, and in the same way the moment of beginning and its duration; despite there being scientific comments from experts on the subject, which support such a procedure and coincidentally claim that the local selfregulation of intestinal motility given the intrinsic potential of its smooth muscle contributes to intestinal peristalsis, which among other factors is not favored by prolonged fasting. Medical evidence has shown that in the vast majority of studies reviewed diet has been beneficial, although the design standard for each type of meta-analysis has not been similar.

Keywords: Dynasty, pharaoh, incest, reproduction, sexuality. 


\section{INTRODUCCIÓN}

En las pretéritas civilizaciones de la Edad Antigua, además de los mundialmente estudiados sistemas de escritura jeroglífica y el demótico (Antiguo Egipto), cuneiforme (Mesopotamia), la escritura brahmi (La India) y los sinogramas o caracteres han (China), las manifestaciones artísticas (en especial las artes plásticas) constituyeron importantes herramientas para la comunicación y el testimonio visual de sucesos, personalidades y esferas de la sociedad como la salud, la educación, la política, la religión y el folklore, aspectos esenciales del peculio cultural acumulado por los pueblos del mundo en su devenir histórico. Ningún acontecimiento de la cotidianidad de dichas sociedades escapó a la memoria enjuiciadora de avezados escribas o al talento ingénito de artesanos, ilustradores de papiros y hacedores de la pintura mural en fachadas y muros interiores de los templos, construcciones domésticas e instalaciones palaciegas $(1,2)$.

Gracias a tales testimonios por ejemplo, podemos constatar en la actualidad cuales eran las conductas sexuales que distinguían las relaciones interpersonales entre individuos de diferentes estratos sociales en el Antiguo Egipto, entre las cuales estaban aquellas prácticas que aunque hoy día pudieran ser consideradas por muchas personas verdaderas transgresiones de los límites morales, para otros constituyen comportamientos habituales enmarcados en el derecho de acción y pensamiento que debe distinguir la cotidianidad de cada ser humano $(3,4)$. La homosexualidad, el incesto, la prostitución, las ceremonias orgiásticas y el adulterio, son los aspectos que más saltan a la vista, existiendo evidencias irrefutables que hacen del emporio civilizatorio del Valle del Nilo uno de los espacios históricos más polémicos en cuanto al comportamiento sexual de sus protagonistas $(5,6)$.

Pero entender cómo funcionaban las dinámicas sexuales y reproductivas en una civilización cuyo entramado sociopolítico sufrió notables transformaciones a lo largo de sus más de tres milenios de existencia, pasa necesariamente por el reconocimiento, en primer lugar, de que lo que hoy se conoce como el Antiguo Egipto fue una sociedad teocrática que alcanzó el grado civilizatorio gracias al régimen social esclavista allí existente, en el cual convergieron en lo fundamental, dos clases sociales: esclavos y hombres libres. La divergencia social de ambos grupos radicaba básicamente en una desigual distribución de los medios fundamentales de producción, donde los primeros eran despojados de todo derecho a la propiedad sobre dichos medios, e incluso sobre sus propias vidas, mientras que los hombres libres a pesar de no constituir una masa homogénea, disfrutaban de algunos beneficios más o menos significativos en dependencia de las riquezas que fueron capaces de acumular (7).

De modo que la totalidad de relaciones sociales que se gestaron en el Antiguo Egipto, dentro de las cuales se insertan las prácticas sexuales, deben evaluarse desde el prisma de la diferenciación clasista, identificando tres tipos de interacciones principales: las establecidas exclusivamente entre esclavos, las que involucraban a esclavos con hombres y mujeres libres, y las concernientes únicamente a este último sector de la sociedad egipcia, al cual pertenecían el faraón, la familia real y la corte, así como los legisladores, el aparato teocrático (sacerdotes), los funcionarios públicos y los terratenientes y comerciantes. Infringir las leyes que imposilitaban las relaciones entre personas de diferente rango social, implicaba severas consecuencias, entre las cuales ninguna superaba la execración de morir sin derecho a defenderse, o pasar el resto de la vida bajo la condición de esclavo.

Lo preliminar no era aplicable a la vida privada del faraón y su entorno cercano, cuya impunidad lo convertía en una divinidad terrenal y en el "dueño absoluto de los hombres" (8), así como en el mayor infractor de las normas de comportamiento cívico, entendiendo el civismo como los patrones elementales de comportamiento social, que nos permiten convivir dentro de determinada colectividad. Veamos a continuación algunos ejemplos representativos que ilustran -en el plano sexual y matrimonial- cuan convulsa e inverosímil podía resultar la coexistencia dentro de la corte faraónica del Antiguo Egipto, como extensión terrenal de una dimensión divina no menos estridente $(1,2)$.

\section{DESARROLLO}

Las prácticas incestuosas, definidas por la ciencia psicológica como el "contacto físico o relación sexual de personas entre las cuales existe una relación de consanguinidad lineal" (9), son tan antiguas como la misma historia de la raza humana, llegando hasta nuestros días célebres testimonios que involucran no sólo a familiares biológicos (padres e hijos, entre hermanos, etc.), sino también a parientes políticos (padres e hijos adoptivos, suegros y yernos, etc.) los cuales reconocen mutuamente la existencia de fuertes lazos de familiaridad a pesar de no haber entre ellos un enlace consanguíneo (4).

La historiografía coincide en que el incesto no sólo era una experiencia ampliamente extendida entre todos los estratos sociales del Antiguo Egipto, sino también que era permitido (10), especialmente dentro de la corte faraónica, cuya finalidad era la de garantizar una línea dinástica pura capaz de concentrar el poder en torno a una sola familia mediante la sucesión hereditaria.

Debido al conocimiento y poder ilimitados que poseía el faraón dentro de una cultura teocrática como la egipcia, resulta comprensible el hecho de que la mitología popular los relacionara simbólicamente con una descendencia ancestral engendrada nada más y nada menos que por los propios dioses, los cuales eran representados gráficamente a imagen y semejanza de los humanos (en algunos casos) y cuyas historias no distaban mucho de las que protagonizaban los mortales faraones. Esta analogía divino-profana se extiende al ámbito sexual incestuoso, donde el ejemplo más conocido es el de Isis y Osiris (Fig.1), quienes encarnaban el espíritu de fecundidad y regeneración, respectivamente, conformando junto a su hijo Horus lo que los historiadores y egiptólogos han denominado como Tríada Osiriaca. Según la cosmogonía heliopolitana ambas deidades además de amantes fueron hermanos, pues eran hijos de Geb (dios creador y principio de vida) y Nut (diosa del cielo y madre de los dioses), quienes curiosamente también eran hermanos (11). 
Figura 1.

Isis (izquierda) y Osiris (Derecha)

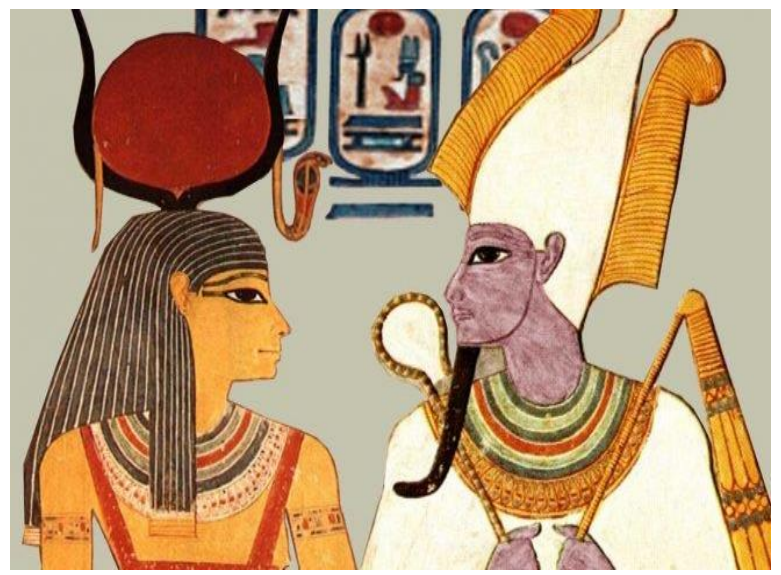

Dsiponible en: https://okdiario.com/curiosidades/isis-osiris-dioses-egipcios-1099246

Siguiendo la lógica secuencial de tales procederes divinos, los faraones, como ya se ha advertido, practicaron fundamentalmente el incesto entre hermanos tras consumar uniones matrimoniales en plena adolescencia. Entre los casos más citados se halla el de Tutankamón (Fig.2), faraón que reinó del 1336 a 1327 a. C. como parte de la dinastía XVIII que inaugura el denominado Imperio Nuevo de Egipto, quien se casó con su media hermana Anjesenamón (eran hijos del mismo padre) tras asumir el poder con tan solo nueve años. Anjesenamón fue la tercera hija de la mítica Nefertiti y del otrora faraón Akhenatón, quien también engendró a Tutankamón en unión de una de las integrantes de su harén real nombrada Kiya, aunque este último nombre y su supuesta maternidad sobre Tutankamón aún permanece entre signos de interrogación para no pocos historiadores (6).

Figura 2.

Tutankamón. Faraón de la XVIII Dinastía

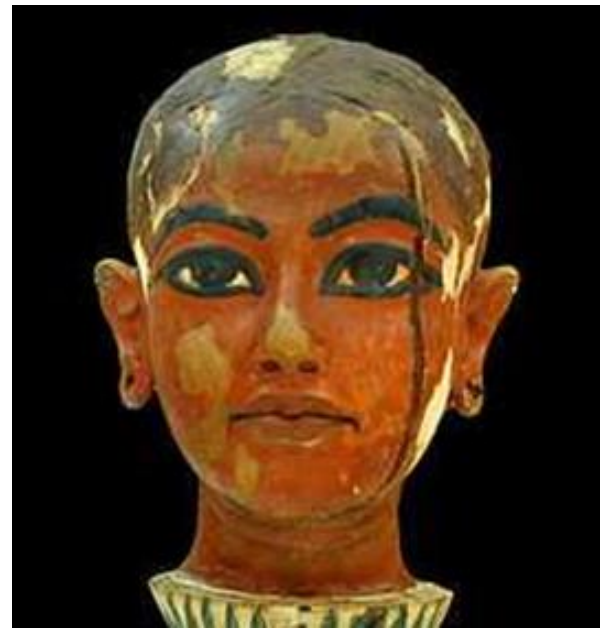

Disponible en: https://supercurioso.com/quien-fue-tutankamon/

Pero el vínculo incestuoso de Anjesenamón supera la relación que sostuvo con el más célebre y el menos significativo de los faraones egipcios, ya que tras la muerte de Tutankamón a los dieciocho años, la Gran Esposa Real se convirtió en cónyuge de su propio abuelo materno nombrado Ay, quien reinó desde el 1327 a 1323 a. C, siendo registrado como el penúltimo faraón de la decimoctava dinastía.
Otro famoso caso de incesto en el Antiguo Egipto es el de la reina Cleopatra VII (Fig.3.), última gran reina del Antiguo Egipto, quien rigió entre los años 51 a. C. y 30 a. C. como postrera representante de la dinastía ptolemaica, que había sido fundada por Ptolomeo I Sóter hacia el 305 a. C. tras la muerte de Alejandro Magno (12). 


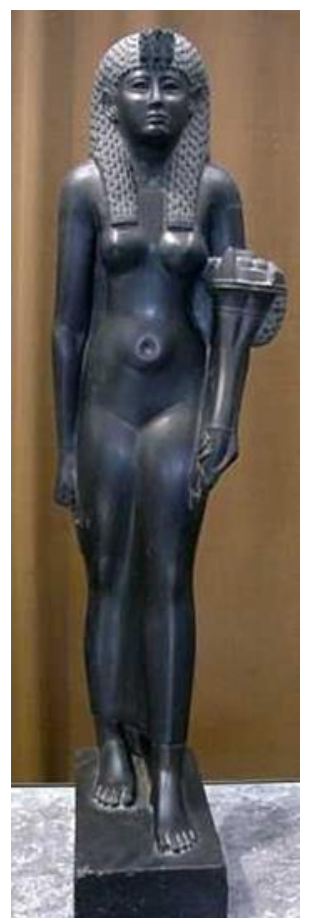

Disponible en: http://190.85.46.51/CONTENIDOS/wikipedia/content/a/cleopatra_vii.htm

Es conocido que los dos primeros matrimonios que sostuvo la acreditada soberana de Egipto, fueron precisamente con sus hermanos (11). La primera de esas uniones duró aproximadamente cuatro años (desde el 51 a.C. hasta el 47 a. C.), y el suceso, más allá de la aludida costumbre de filiación incestuosa que singularizaba los lazos sentimentales en la familia real, llama la atención no sólo por la brevedad del consorcio, sino también por la juventud con que los protagonistas contrajeron nupcias, ya que Cleopatra VII contaba con solamente dieciocho años mientras que su hermano Ptolomeo XIII tenía doce. Tras la muerte de éste, la reina egipcia volvió a casarse con otro de sus hermanos (Ptolomeo XIV), aunque dicha unión superó en brevedad al anterior matrimonio, pues solamente se extendió por el reducido periodo de tres años debido al repentino deceso de quien había sido declarado corregente tras la desaparición de su hermano Ptolomeo XIII.

Los progenitores de Cleopatra VII (Ptolomeo XII y Cleopatra V) quienes habían gobernado como faraón y reina corregente respectivamente), también incurrieron en el incesto, ya que ambos eran hermanos y mantuvieron una unión matrimonial durante varios años, engendrando además de Cleopatra VII, a Cleopatra VI y el referido Ptolomeo XIII.

Gracias al ostensible desarrollo experimentado por disciplinas como la genética y la psicología evolutiva, ya se ha podido demostrar en el presente que las relaciones incestuosas desencadenan efectos contraproducentes a nivel psicológico y cromosómico, pues tales prácticas incrementan la posibilidad de aparición de genes negativos recesivos en las generaciones descendientes. Dicho detalle ha sido constatado además por la ciencia antropológica, a partir de la ejecución de ensayos etnográficos in situ en poblaciones humanas que históricamente han practicado el incesto, en las cuales se ha verificado (mediante mediciones antropométricas) como se ha reducido la estatura de los individuos examinados, luego de compararlas con las dimensiones de sus antecesores, registradas en las fuentes históricas (13-17).

La reducción de la talla (enanismo) es una de las alteraciones genéticas más asociadas con la descendencia engendrada por las relaciones incestuosas, la cual origina una lógica depresión endogámica, asumida esta como la ausencia de patrones de adaptabilidad (la fecundidad, por ejemplo) que son el resultado de la pérdida de la variación genética, al estar presente la condición homocigótica en el nuevo individuo que acaba de nacer (homocigótico recesivo).

De todo lo anterior, se intuye la posibilidad de que los faraones egipcios, así como sus cortesanos y familiares más inmediatos, hayan experimentado a lo largo de los siglos las secuelas ocasionadas por el nocivo comportamiento incestuoso. Tutankamón, faraón imputado en el presente texto y cuya existencia se vio doblemente marcada por el hábito incestuoso (debido a su ascendencia y a la relación que sostuvo con su media hermana Anjesenamón), es uno de los personajes del Antiguo Egipto que más suele relacionarse con los padecimientos y enfermedades generadas por los antecedentes incestuosos de la dinastía a la cual pertenecía.

El hallazgo de su cripta funeraria en 1922 gracias al trabajo desplegado por el arqueólogo inglés Howard Carter (18741939), permitió acceder al sarcófago donde se conservaban sus restos momificados en perfecto estado, los cuales han sido sometidos desde entonces a sucesivos exámenes de laboratorio con la finalidad de descubrir en primera instancia, cual había sido la verdadera causa de su fallecimiento, además de la naturaleza patológica de ciertos trastornos dismórficos que evidenciaba su cuerpo.

En 2010 el Ministerio de Cultura de Egipto, en voz del Consejo Supremo de Antigüedades de dicha nación, coordinó la 
realización de una serie de estudios genéticos a los restos de Tutankamón los cuales se conservaban en el Museo Egipcio del Cairo. Los resultados, publicados en la revista Journal of the American Medical Association (JAMA) y llevados a cabo durante más de dos años, corroboran que Tutankamón murió a causa del Mal de Köhler (tipo de osteocondrosis) cuya sintomatología se vio agravada producto de la malaria que contrajo.

Por su parte, la disciplina iconográfica revela dentro de los estudios de Historia del Arte, que, pese a que "en la pintura egipcia la forma de dibujar la figura humana no era en absoluto realista, sino más bien estructural" (18-22), la anatomía de Tutankamón que podemos apreciar en los retratos que se le realizó, sugiere la existencia de cierto rasgo andrógino en su físico, producto quizás de la ginecomastia (aumento de las mamas en varones) que determinados especialistas han percibido en él. Otra de las posibles enfermedades que se han propuesto a partir de su apariencia en esculturas y grabados es el Síndrome de Klinefelter, anomalía cromosómica caracterizada por una alteración genética que se desarrolla por la separación incorrecta de los cromosomas homólogos, detalle que pudiera estar relacionado con los precedentes incestuosos de la dinastía XVIII del Imperio Nuevo, a la cual perteneció Tutankamón.

Otros investigadores por su parte, sostienen la hipótesis de que Akhenatón, progenitor de Tutankamón y de su media hermana Anjesenamón, padeció las secuelas del Síndrome de Marfan $(13,15), u$ otro tipo de enfermedad degenerativa que provocase también una particular representación dentro de la iconología egipcia (23-25), teniendo en cuenta en ambos casos, el examen detallado de la estructura ósea del gobernante (26-28).

\section{CONSIDERACIONES FINALES}

El hecho de que en algunos pasajes mitológicos del Antiguo Egipto se abordara el incesto (fundamentalmente entre hermanos) como una práctica normal, justifica que en la dimensión profana, los faraones (quienes se adjudicaban un nexo divino con el panteón teológico) imitaran tal proceder dentro de sus cortes, existiendo como segunda causa, la estratégica intención de perpetuar el poder familiar a través de la sucesión lineal de descendientes emparentados de forma consanguínea (dinastía) (28).

Dicha percepción y/o asimilación conductual del incesto ha variado con el paso del tiempo y la conformación de nuevas formas de relaciones sociales. En la actualidad la mayoría de los países han dado su aprobación al denominado tabú del incesto, nombre con el que se ha bautizado a "un mecanismo para evitar el incremento de afecciones hereditarias en la comunidad, las cuales aumentarían de permitirse el contacto sexual entre individuos emparentados" (29). Tal argumento ha sido mundialmente manejado a partir de las exploraciones empíricas que realizara a mediados del pasado siglo el antropólogo francés Claude Lévi-Strauss (1908-2009), quien logró concluir que "el tabú del incesto ha sido el mecanismo cultural que ha permitido organizar la reproducción biológica de nuestra especie" (30).

No obstante, y pese a que en no pocos sistemas legislativos a nivel mundial se considera el incesto como un delito, el debate global que han seguido suscitando algunas noticias en las que se revelan vínculos incestuosos en pleno siglo XXI, encarnizan aún más la polémica en torno a si se deben incrementar o no las sanciones penales a los individuos, que, siendo mayores de edad y con absoluta capacidad mental, han incurrido en conductas sexuales con familiares consanguíneos.

\section{REFERENCIAS}

1. Cuervo AB. La sociedad en el Egipto de los faraones. Historia Digital.2017; 17 (29):155-186. Disponible en: https://dialnet.unirioja.es/servlet/articulo?codigo $=5771481$

2. Parra JM. La agitada vida de las momias. Revista Historia. 2010; 135(May):18-28. Disponible en: https://dialnet.unirioja.es/servlet/articulo?codigo $=6336867$

3. Fernández M, Beraldo S. La propaganda en el mundo antiguo: Egipto. La política a través del arte faraónico.2016. Disponible en: http://hdl.handle.net/10651/38217

4. Foucault M. Historia de la sexualidad. 2001;Vol. 3. siglo XXI. Disponible en: https://repositorio.ufsc.br/bitstream/handle/123456789/1226/foucault historiadasexualidade.pdf

5. Valdivia HL, Nazario DA, García OL. La medicina como tema de representación en la historia de la pintura. Apuntes para una iconografía necesaria. (I-. Las grandes civilizaciones de la antiguedad). Mediciencias UTA.2017;1(2):29-36. Disponible en: https://medicienciasuta.uta.edu.ec/index.php/MedicienciasUTA/article/download/8/20

6. Strauss JA. L'Achat et la vente des esclaves dans l'Egipte.Leipzig. 2000. Disponible en: http://hdl.handle.net/2268/25180

7. Bonnassie, P. Supervivencia y extinción del regimen esclavista en el Occidente Medieval durante la Alta Edad Media: Siglos IV-XI. Boletín de Historia Social Europea 1. 1989: 53-107. Disponible en: http://creativecommons.org/licenses/by-ncnd/2.5/ar/

8. Correlativo, Espacio Curricular. Espacio Curricular: Historia Medieval. Diss. Universidad Nacional de Cuyo, 2015. Disponible en: http://200.12.134.72//MG/pdf/- UNIV - Lucero Mampel H MED 15.pdf

9. Gallegos, Miguel. (2018). La Difusión Enciclopédica de la Psique en América Latina: Diccionarios Para la Enseñanza (19162000). Psykhe (Santiago). 2018;27(1):1-20. Disponible en: https://dx.doi.org/10.7764/psykhe.27.1.1040

10. Vera, L. Historia de la sexualidad. Rev.Biomed.1998;9:116-121. Disponible en: http://www2.udec.cl/ erhetz/privada/sexualidad/unidad 01/historia sexualidad.pdf

11. Hopkins, K. Brother-Sister Marriage in Roman Egypt. Comparative Studies in Society and History, 1980; 22 (3): 303-354. Cambridge University PressStable.. Disponible en: https://www.jstor.org/stable/178753

12. Parra JM. Reinas de Egipto: la mujer en la Corte de los faraones. La Aventura de la historia. 2018: 48-52. Disponible en: https://dialnet.unirioja.es/servlet/articulo?codigo $=6541070$

13. Evans BT. De Tutankamón de Tebas a la genómica y biología molecular. Acta Médica Costarricense. 2015; 57(4): 160-162. Disponible en: https://www.scielo.sa.cr/scielo.php?pid=S0001-60022015000400160\&script=sci arttext\&tlng=en 
14. Ledermann W. Una mirada crítica sobre la medicina en el Antiguo Egipto. Revista chilena de infectología.2016;33(6):680685. Disponible en: https://scielo.conicyt.cl/scielo.php?pid=S0716-10182016000600011\&script=sci arttext\&tIng=en

15. Souto, I. La ruptura de Amarna: hechos, teorías, causas y consecuencias. En: Construyendo la Antigüedad. Actas del III Congreso Internacional de Jóvenes Investigadores del Mundo Antiguo (CIJIMA III). Centro de Estudios del Próximo Oriente y la Antigüedad Tardía (CEPOAT). 2016;13-54. Disponible en: https://dialnet.unirioja.es/servlet/articulo?codigo=7297008

16. Huebner, SR. Brother-sister'marriage in Roman Egypt: a curiosity of humankind or a widespread family strategy?. The Journal of Roman Studies. 2007;27: 21-49. Disponible en: https://www.jstor.org/stable/20430570?seq=1

17. Polo, MAM. Templo y cosmos. Arte y sociedad del Egipto antiguo. Encuentro, 2000;171:60-94. Disponible en: https://dialnet.unirioja.es/servlet/articulo?codigo $=6836042$

18. Leavitt, GC. Sociobiological explanations of incest avoidance: A critical review of evidential claims. American Anthropologist 1990; 92.(4): 971-993. Disponible en: https://anthrosource.onlinelibrary.wiley.com/doi/abs/10.1525/aa.1990.92.4.02a00070

19. Soto, Iskra Pavez. "El incesto como tabú y la liberación de la víctima." Athenea Digital. Revista de pensamiento e investigación social. 2020;20(3): 285-300. Disponible en: https://atheneadigital.net/article/view/1966

20. Albalat, D. La Mujer en el antiguo Egipto. $2007 . \quad$ Disponible en: \begin{tabular}{llllll} 
http://repositori.uji.es/xmlui/bitstream/handle/10234/78471/forum 2007 & 24.pdf?sequence $=1$ & & \\
\hline Morales Loo, MM. & El Incesto: & Consideraciones & Psicoanalíticas. & Disponible & en:
\end{tabular} http://www.psicopolis.com/psicopedia/lacanincesto.pdf

22. Zingarelli, A. Extranjeros en Egipto: extraneidad e integración durante el Imperio Nuevo. Ponencia. Tercer Congreso Nacional de la Asociación Latinoamericana de Estudios de Asia y África (ALADAA). 2008. Villa La Angostura, Argentina. Disponible en: http://www.aladaa.com.ar/2008/Archivos/Ponencias/ponencia\%20Zingarelli.ttf

23. Martos, JA. El retorno de Tutankamón: últimas noticias sobre el faraón más popular. Clío: Revista de historia. 2007;27:4253. Disponible en: https://dialnet.unirioja.es/servlet/articulo?codigo $=2392190$

24. White OA., Campos ChK. El incesto: su perspectiva histórica y jurídica. Medicina Legal de Costa Rica 2004; 21(2): 21-36. Disponible en: https://www.scielo.sa.cr/scielo.php?pid=S1409-00152004000200005\&script=sci arttext.

25. Cardenas Q, Eloisa M, Karen M H. and Gutiérrez S. Perspectiva del incesto: Naturaleza y cultura. Diss. Universidad de Cartagena, 2011. Disponible en: http://hdl.handle.net/11227/1638

26. Lucas, A. Ancient Egyptian materials and Industries about 1350 BC. Analyst. 1993; 58(692): 654-664. Disponible en: https://pubs.rsc.org/en/content/articlelanding/1933/an/an9335800654/unauth\#!divAbstract

27. Sánchez Barragán, E. Gabriel, Las siete Cleopatras del Nilo. Una dinastía femenina en el Egipto de los Ptolomeos. Nova Tellvs. 2020;38(2):241-247. Disponible en: filologicas.unam.mx/nouatellus/index.php/nt/article/view/859/1167

28. Rosado Millán, Mํㅡㄹ Jesús; García García, Francisco; Alfeo Álvarez, Juan Carlos; Rodríguez Rosado, Javier. El suicidio masculino: una cuestión de género. Prisma Social. 2014;(13):433-491. Disponible en: https://www.redalyc.org/pdf/3537/353744532013.pdf

29. Hamy, M., et al. Questionnaire de sociologie et d'ethnographie. Bulletins de la Société d'Anthropologie. 1889; 24. Disponible en: https://halshs.archives-ouvertes.fr/halshs-00848795/

30. Moreno García JC. Élites provinciales, transformations sociales et idéologie à la fin de l'Ancien Empire et à la Première Période Intermédiaire. MOM Éditions. 2005; 40(1): 215-228. Disponible en: https://www.persee.fr/doc/mom 195549822005 act 4012401 